Paidéia, 2004, 14(29), 347-357

\title{
PATERNIDADE: CONSIDERAÇÕES SOBRE A RELAÇÃO PAIS-FILHOS APÓS A SEPARAÇÃO CONJUGAL ${ }^{1}$
}

\author{
Cristina Dantas \\ Bernardo Jablonski ${ }^{1}$ \\ Terezinha Féres-Carneiro \\ Pontifícia Universidade Católica do Rio de Janeiro
}

\begin{abstract}
Resumo: O presente trabalho busca investigar a construção e a manutenção do vínculo afetivo entre pai e filhos após a separação focalizando a questão da paternidade e a da própria formação da identidade masculina, além, é claro, do que se sabe hoje acerca da "paternidade à distância” e de seus efeitos sobre os filhos. Com a família contemporânea em franco processo de reformulação, presenciamos um crescente intercâmbio entre as funções materna e paterna, já que nos dias de hoje tanto os homens quanto as mulheres dividem seu tempo entre o trabalho fora de casa e os cuidados destinados aos filhos. Além disso, o divórcio e, posteriormente, o recasamento dos componentes da família criam uma teia complexa de relacionamentos que necessita ser estudada, principalmente no que diz respeito ao papel a ser exercido pelos homens, como pais separados e sua relação para com seus filhos.
\end{abstract}

Palavras-Chave: paternidade; divórcio; identidade masculina; papéis de gênero.

\section{FATHERING: SOME CONSIDERATIONS ABOUT THE RELATHIONSHIP BETWEEN FATHERS AND CHILDREN AFTER DIVORCE}

\begin{abstract}
The purpose of this paper is to investigate the formation and preservation of the affectionate union between the fathers and their children during a post-divorce or separation period, focusing on fathering and the formation of masculine identity, as well as what we know today about "distant fathering" and its effects on children. The family today is in an unmistakable process of change and all of us are witnesses of a growing interchanging course between the traditional roles of the father and the mother, who are forced to manage their time between working and taking care of their children. Divorce and remarriage thereafter create a complex web of relationships within the family that must be studied, mainly regarding the roles performed by men as divorced fathers and the relationship with their children.
\end{abstract}

Key-Words: fathering; divorce; masculine identity; gender roles.

A questão da paternidade vem ganhando destaque como foco de pesquisas, devido às demandas atuais em se compreender a importância de uma nova elaboração das funções paterna e materna na sociedade (Boechat, 1997; Brasileiro, Jablonski e FéresCarneiro, 2002; Cowan \& Cowan, 2000; Lewis \& Dessen, 1999; Sanchez e Thompson, 1997; Walzer, 1998). O tema surge juntamente com a deflagração de uma crise da masculinidade que, de acordo com Nolasco (1993), encontra seu fio condutor na pater- nidade: através da relação com os filhos, de sua participação na casa, o homem revive experiências circunscritas ao seu ambiente familiar de origem. E o exercício da paternidade, incluindo cuidados corporais e necessidades afetivas dos filhos, pode ser um caminho para a construção de um novo homem, pois uma das características do modelo tradicional de masculinidade, é a dificuldade que eles têm de expressar afeto e ternura.

Goldenberg (2000) levanta a possibilidade de

\footnotetext{
${ }^{1}$ Artigo recebido para publicação em 11/02/2004; aceito em 05/08/2004.

${ }^{1}$ Endereço para correspondência: Bernardo Jablonski, Rua João Borges, 89/102, Gávea, Rio de Janeiro, RJ, 22451-100, E-mail: bjablonski@uol.com.br
} 


\section{Bernardo Jablonski}

os homens, hoje, viverem uma situação inversa àquela em que foram criados. Até algum tempo atrás, os relacionamentos entre pais e filhos eram marcados pelo distanciamento e por uma postura autoritária dos pais. Hoje, assiste-se a uma proximidade do contato, incentivando a demonstração de afeto e a participação ativa, durante o crescimento das crianças. Ainda segundo a autora, estar-se-ia presenciando maior flexibilidade nos papéis paterno e materno, que podem sair dos estereótipos rígidos e experimentar novas situações.

Salem (1987) apresenta “O casal grávido” como um novo ideal de participação do homem como genitor. Nesse padrão, espera-se que ele acompanhe, ativamente, todo o processo de gravidez e parto, incluindo cursos de preparação, com um investimento afetivo igual ao da mulher. O filho é visto como indivíduo psíquico que precisa deste novo pai, mais próximo e envolvido com sua criação e cotidiano e a autora conclui que, mais do que maternidade e paternidade, o projeto do “casal grávido" diz respeito a um ideal de conjugalidade igualitária.

Em relação à paternidade, Fein (1978) apresenta três perspectivas diferentes: a tradicional, a moderna e a emergente. Na tradicional, encontra-se o pai como provedor, que oferece suporte emocional à mãe, mas não se envolve diretamente com os filhos, exercendo o modelo de poder e autoridade. Já a moderna enfatiza seu papel no desenvolvimento moral, escolar e emocional. E a emergente origina-se na idéia de que os homens são, psicologicamente, capazes de participar ativamente dos cuidados e criação das crianças. O autor também afirma, com base em pesquisas realizadas, que para alguns homens o divórcio pode ser uma boa oportunidade para aproximálos dos filhos. Assim, ele enfatiza a importância do pai no desenvolvimento da criança, da aquisição da identidade de gênero até a performance acadêmica.

Lewis e Dessen (1999), ao analisarem os fatores que influenciam no envolvimento dos pais na vida em família, lembram que o contato paternal com as crianças pode assumir formas diferentes em função de fatores como desemprego, trabalho da esposa, divisão de trabalho entre os genitores, etc. Além disso, os autores lembram que qualquer exame mais detalhado da paternidade deve levar em conta as interações familiares e os contatos de cada membro da família com os processos culturais em ação, o que torna a análise em questão bem complexa. Outros pesquisadores vêm, ao longo da última década, explorando a idéia de que a vida das crianças pode ficar melhor caso tenham a oportunidade de manter relacionamentos com adultos de ambos os sexos (Amato \& Keith, 1991; Amato \& Booth, 1997, Arditti, 1999; Greenberg \& O’Neill, 1990).

Corneau (1995) ao abordar o ponto em discussão, ainda que sob uma perspectiva teórica calcada na Psicologia Analítica, afirma que o medo da intimidade, a falta de contato com os próprios sentimentos e a agressividade reprimida constituem-se em problemas cruciais, pois, se o homem não tem relação com seu pai não consegue estabelecer sua própria identidade; segundo ele, a criança precisa reconhecer-se nos pais e ser reconhecida por eles, construindo, a partir daí sua própria identidade. Quando isto não acontece, o sujeito irá buscar uma segurança exterior, para compensar a insegurança interior relativa a sua identidade. Ainda de acordo com o autor, a paixão do homem pelo poder significa a necessidade de se apoiar em algo para provar aos outros sua masculinidade. Essa máscara aprisionaria a sensibilidade masculina, ao mesmo tempo em que manteria o homem escravo dos modelos sociais.

Corroborando este ponto de vista, pode-se supor que um pai presente, além de servir de referência acerca do universo masculino, seria alguém capaz de dar ressonância de forma positiva às questões emocionais, sociais, afetivas e cognitivas dos filhos. Interessante observar que o modelo tradicional de pai, calcado na figura autoritária que exige disciplina a qualquer custo, parece estar sendo, aos poucos, reformulado (Aldous, Mulligan \& Bjarnason, 1998). A discussão em torno da nova identidade masculina vem crescendo, dentro e fora do âmbito acadêmico, tornando-se alvo de debates na sociedade contemporânea.

As demandas agora parecem estar mudando o modelo tradicional de pai distante, provedor e autoritário, dando lugar a alguém participativo, envolvido nas questões de sua prole. São transformações significativas, que remexem sentimentos e relacionamentos e fazem com que, ao se tornar pai, o homem procure resgatar a experiência que teve com o seu próprio pai, o que pode gerar sofrimento e desconforto 
(Dantas, 2003).

Para Corneau (1995), o pai tem três papéis a desempenhar com os filhos. Primeiro é o de "separar” a criança de sua mãe e vice-versa; ele entra na vida dos dois, rompendo a simbiose estabelecida e coloca um limite na vida da criança ao reivindicar a mãe para si próprio também, estabelecendo uma relação triangular pai - mãe - filho que implica em conflitos, mas que são fundamentais e construtivos, se vivenciados de modo saudável e respeitoso. Quando o pai recusa esse papel "conflitogênico" que lhe foi conferido, cria uma enorme dificuldade na organização dessa tríade familiar.

O segundo papel apresentado por Corneau (1995) é o de ajudar a confirmar a identidade de seu filho ou filha. O investimento paterno ao menino e à menina lhes dá segurança e auto-estima. Winnicott (1982) destaca sua importância, não só como apoio emocional à mãe (através de uma boa relação entre ambos), mas como a pessoa que sustenta a lei e a ordem na vida da criança (na interação que estabelece com os filhos e experiências compartilhadas), e à medida que se oferece como objeto de identificação.

O terceiro papel do pai seria o de transmitir "a capacidade de receber e de interiorizar os afetos, de carregá-los consigo" (Corneau, 1995, p.51). Esse contato aproxima pais e filhos, gera cumplicidade, além de uma relação baseada em emoções. As experiências cotidianas de intimidade, juntamente com o exercício dos papéis propostos pelo autor, ajudariam o pai a se vincular aos filhos de forma genuína e salutar.

Para os autores que estudam hoje esta questão (Ramires, 1997; Jablonski, 1998; Oliveira, 1998; Nolasco, 1995, 2000; Brasileiro, Jablonski \& FéresCarneiro, 2002; Dantas, 2003; Felzenszwalb, 2003), a identidade masculina, afirmada através da força e da invencibilidade, vem sendo questionada, abrindo possibilidades para o homem entrar em contato com um universo desconhecido; mas ele estaria fragilizado, porque não sabe lidar de forma mais precisa com suas emoções, além de não ter aprendido a expressar seus sentimentos do modo que hoje se julga mais adequado. Isto se traduz, por exemplo, na dificuldade em se mostrar inseguro e com medo, visto que foi educado para dar conta de tudo, “sem tugir nem mugir”. Já a mulher, estimulada historicamente a agir de maneira mais delicada, teria mais condições em suas relações sociais e familiares.

Entrelaçado à questão da identidade masculina, conforme a influência de perspectivas teóricas oriundas da década de 70 (Lewis \& Dassen, 1999; Nolasco, 1993 e Russel, 1978), o exercício da paternidade implica em grandes desafios, esteja o pai em uma família monoparental, biparental, ou reconstituída. Para Dorais (1994), um primeiro desafio relaciona-se à constância da figura parental que, mesmo diante das mudanças familiares e sociais, deverá constituir um vínculo com os filhos. Outro, de igual importância, diz respeito à adaptação face à emancipação feminina, que requer o pai mais presente na vida dos filhos, dividindo tarefas, impondo limites, juntamente com a mãe, com práticas que possibilitam a participação de ambos, complementares e voltadas a um compromisso com o bem-estar das crianças.

\section{Paternidade - das atitudes ao comportamento}

Segundo Jablonski (1998), os efeitos da emancipação feminina junto aos homens podem ser divididos em duas áreas: das atitudes e dos comportamentos. Quanto à primeira, nota-se um crescente interesse deles em participar, cada vez mais, da educação e cuidados com os filhos. Mas, no campo dos comportamentos, a divisão de tarefas parece utopia, com uma promessa de mudança que não é cumprida, aumentando a frustração das mulheres.

De acordo com pesquisa levada a cabo pela CNSR (Le Monde em 2000), 80\% dos pais, apesar do discurso igualitário, na prática, não participam em quase nada da educação e cuidados infantis e menos ainda dos afazeres domésticos. A pesquisa em questão, com mil pais entrevistados, mostra a diferença entre as bem intencionadas atitudes igualitárias e a prática do dia-a-dia, sendo a distribuição de tarefas na casa ainda bastante marcada pela divisão sexual, com as mulheres arcando com a maior parte delas.

Por outro lado, Pleck (1997) confirma, em suas pesquisas, que a mulher tem convocado cada vez mais seu companheiro a participar dos cuidados destinados à prole. $\mathrm{O}$ autor encontrou fatores que podem ajudar ou atrapalhar o homem para se fazer presente, como a idade (filhos pequenos sensibilizam mais que os adolescentes), o sexo dos filhos (meninos re- 


\section{Bernardo Jablonski}

ceberiam mais atenção) e o dia da semana (fins-desemana seria o momento mais apropriado para o pai exercer sua função). Diante deste quadro, muitas mulheres sentem-se sobrecarregadas, visto que a divisão igualitária dos papéis não acontece na prática, contribuindo para que ela se veja solitária nas funções diárias. Jablonski (1999) coloca que a passagem das atitudes ao comportamento não tem ocorrido satisfatoriamente, qualitativa ou quantitativamente. O homem parece confuso diante de tantas mudanças e a elaboração do novo papel ocorre lentamente. Assim, uma divisão mais igualitária de funções parece ser o primeiro passo em direção a mudanças eficazes.

À medida que os filhos crescem, apesar de possíveis atitudes igualitárias pré-existentes, a divisão de trabalhos dentro do lar tende a ficar mais estereotipada, quebrando a igualdade total defendida pelos jovens solteiros de ambos os sexos (Bryant e Zick, 1996).

A disparidade de papéis pode ser vivenciada pelas mulheres de forma bastante dolorosa, uma vez que quebra a promessa de igualdade de funções, alimentada por atitudes dos próprios homens, o que se constitui em uma fonte adicional de conflitos, numa área já carregada de problemas. Para as mulheres mais diretamente as de classe média, em contexto urbano, isoladas, com poucos parentes e tendo como companhia constante apenas vizinhos quase que indiferentes - o que resulta é um agravamento de sentimentos negativos: solidão, tédio, aborrecimento, cansaço e tensão (Coontz, 1997; Jablonski, 1998).

Outros pesquisadores reforçam com seus dados esta diferença entre opiniões e ações. Assim, Coverman e Sheley (1986) observaram, em seus estudos nos anos 60 , que os homens despendiam apenas quinze minutos diários nos cuidados aos filhos. Demo (1992) assinala que de lá para cá a participação masculina tornou-se mais efetiva, principalmente entre os pais com menos de 30 anos de idade ou com filhos pequenos. No entanto, ele mesmo reconhece que as mudanças não têm sido as esperadas, embora tenda a aumentar, com os filhos adolescentes recebendo mais atenção do que quando bebês.

Atkinson e Blackwelder (1993) procuraram observar a evolução do tema paternidade ao longo do século XX, tal como foi exposto em revistas norteamericanas populares (Life, Look e People), genéricas (Fortune e New Yorker) femininas (Harper's Bazaar e Good Housekeeping) dirigidas à família (Child Today e Parents) e de notícias (Newsweek, Time) e concluem que tanto o interesse na paternidade quanto sua definição flutuaram significativamente ao longo do século. ${ }^{3}$ De qualquer modo, esta análise de conteúdo também apontou para o fato de que, flutuações à parte, toda vez que a participação feminina na força de trabalho cresceu, ou a taxa de fertilidade desceu, houve maior preocupação da opinião pública com a função paterna.

Estudo similar levado a cabo por LaRossa, Gordon, Wilson, Bairan e Jaret (1991), chegou a resultados similares, mas não iguais. Suas reflexões basearam-se no material publicado sob a forma de cartoons no Saturday Evening Post, de 1922 a 1968, e de 1971 a 1978. O título do artigo - "The Fluctuating Image of the 20th Century American Father" - revela que a competência ou não dos pais no trato com os filhos, retratadas comicamente, não seguiu a lógica de acompanhar gradual e linearmente mudanças sociais significativas, como a entrada da mulher na força de trabalho ou o aumento do igualitarismo. Para estes autores, fatores culturais, além do papel exercido pelas duas grandes guerras, a Depressão e uma nova visão de família interagiriam para tornar nebulosa a evolução da função paterna tanto nos EUA, como em outros países do Ocidente. Deve-se levar em conta, no entanto, que este trabalho de LaRossa baseou-se no humor, área por excelência excessivamente crítica, e mais preocupada com exageros risíveis do que com o retratar isento da realidade.

Assim, a mídia, ao mesmo tempo que capta, influencia reflexivamente o caminho a ser trilhado, e o que pode ser dito das Artes em geral (notadamente o cinema). Já em meados do século XIX, o movimento de industrialização havia cristalizado a feminilização de tudo que se relacionava à esfera doméstica, bem como a marginalização dos pais no tocante ao envolvimento com os filhos. Para Phares (1996), esta tendência perdurou até os anos 70, quan-

\footnotetext{
3 “Solucionador de problemas, protetor, provedor, modelo de comportamento e de recreação e confidente” foram as principais imagens de pai alternadamente ventiladas nas revistas de maior circulação nos EUA.
} 
do os pais começaram a ser convocados para suas novas missões.

\section{A Relação entre pais e filhos após a separação}

Com relação à separação, Ramires (1997) relatou ter encontrado, em sua pesquisa com pais separados, a afirmação de que o relacionamento com os filhos vai melhorando qualitativamente, após o divórcio, pois o tempo passado juntos é realmente dedicado às crianças, o que proporciona um aumento na intimidade e cumplicidade entre pais e filhos. Podemos supor que, devido à diminuição do contato existente entre o pai e os filhos, após a separação, ele busque uma vivência de maior qualidade, justamente para compensar a sua ausência diária. A autora também afirma que todos os homens participantes de sua pesquisa tinham como referência, ao se relacionar com os filhos, seus próprios relacionamentos com os pais. Eles confirmaram que o exercício da paternidade também depende das experiências vividas com seus pais e de como introjetaram o modelo paterno. Embora criados dentro da visão tradicional de papéis familiares, surge no discurso masculino uma preocupação em reformular o modelo vivenciado, ao invés de simplesmente o reproduzirem.

Fein (1978) também relata que para alguns homens o divórcio é a oportunidade de se aproximar e participar ativamente na criação de seus filhos. Aqui vale ressaltar uma certa ambivalência na postura das mães a esse respeito, pois, se por um lado exigem maior participação do pai na vida dos filhos, por outro, existe uma resistência em deixá-los agir. A distância existente entre as atitudes e o comportamento, sugerida por Jablonski (1999), também engloba o universo feminino.

Em muitos casos, a dificuldade em se lidar com a separação, assim como o próprio processo de desvincular-se do relacionamento, pode colaborar para que as mães dificultem o contato entre pais e filhos. O afastamento físico dos filhos pode gerar uma série de conflitos e ansiedades nesses pais, em primeiro lugar, porque essa vivência atual os remete ao próprio relacionamento com seus pais. Em segundo, porque pode haver uma série de expectativas (irreais) em relação à constituição da sua própria família e à criação dos filhos. Em suma, aspectos de relaciona- mentos anteriores introjetados somam-se aos aspectos práticos para formar o tipo de pai que cada um pode e quer ser.

Furstenberg e Nord (1985), pesquisando acerca dos cuidados que o pai/mãe biológico exercem, à distância, e de novos padrões de criação dos filhos, após o rompimento do casamento, revelam que a sociedade parece não estar preparada para lidar com as mudanças ocorridas no perfil da família contemporânea. De acordo com as estatísticas apresentadas no artigo dos autores supracitados, quase a metade dos casamentos atuais termina em separação. Com isso, a expectativa de permanência conjugal deu lugar a um padrão de sucessões conjugais, já que a maioria dos indivíduos irá casar-se novamente, dados plenamente confirmados por pesquisas mais recentes, tanto no que diz respeito aos índices de separação quanto aos de recasamento (Coontz, 1997).

Estes mesmos autores afirmam que, ao contrário de outros pesquisadores que, como vimos anteriormente, vêem na separação a possibilidade do estreitamento dos laços entre pais e filhos, o recasamento do pai pode vir a reduzir o convívio com os filhos biológicos de casamentos anteriores, reafirmando a idéia de que essa teia complexa de relacionamentos está expandindo-se, cada vez mais, e que a paternidade biológica pode estar perdendo terreno (no caso da separação) para a paternidade social, isto é, possibilitando que a criança crie laços afetivos com outras figuras masculinas (o namorado ou novo marido da mãe, algum parente próximo que exerça a função paterna).

De fato, o recasamento cria relacionamentos ainda mais complexos, pois pais/mães biológicos precisam aprender a compartilhar seus filhos com os pais/ mães sociais. Desse modo, a sucessão conjugal aumenta a lista das pessoas envolvidas nos cuidados e na educação dos filhos. Mas os filhos, em geral, têmse mostrado habilidosos ao lidar com essa complexidade, pois, ao perceberem o comprometimento com a manutenção do relacionamento por parte dos pais que não obtêm a custódia, eles reconhecem o envolvimento e aprendem a lidar com a situação (Amato, 1994; Dantas, 2003; Glick, 1984; Souza, 2000).

A pesquisa de Furstenberg e Nord (1985), embora realizada há quase vinte anos, mostra-se bas- 


\section{Bernardo Jablonski}

tante atual, pelo menos com relação a alguns de seus aspectos centrais (Bertaux \& Delcroix, 1992; Dantas, 2003). Assim, a maioria dos pais, após a separação, não procurou manter contato regular com os filhos: $49 \%$ das crianças afirmaram não ter estado com o pai não-residente durante o ano anterior. $\mathrm{E}$ apenas uma, em cada seis, afirmou manter contato semanal com o pai. Os dados relativos a essa pesquisa apontaram para o papel limitado exercido pelos pais que não moram com seus filhos, já que três entre cinco crianças não tinham visto seus pais biológicos nãoresidentes, no último mês. No entanto, em caso de separação recente, é mais provável que a criança se encontre um número maior de vezes com o pai/mãe que não obtém a guarda. Exceto pelo período que sucede, imediatamente, à separação, as crianças comentam a falta de contato com os pais. A média de apenas duas visitas por mês pode indicar a existência de um estado transitório para alguns pais não-residentes entre um período de envolvimento intenso e, posteriormente, a um de maior distanciamento (devido ao recasamento ou por alguma possível mudança geográfica, algo mais comum nos Estados Unidos do que no Brasil).

A maioria das crianças relatou, no estudo em questão, não dormir na casa do pai não-residente e não ter lugar para guardar roupas e objetos pessoais nela. Mais da metade dos entrevistados (58\%) disseram jamais ter visitado a casa nova. Os telefonemas também são esporádicos, assim como as visitas, que tendem a diminuir, à medida que aumenta o tempo da separação. Embora sugerida na mídia, os filhos de casais separados, raramente, têm duas casas. Outra constatação demonstra a característica dos encontros, em sua grande maioria voltados para o lazer. Aqui, vemos que a participação do pai não-residente nos trabalhos escolares ou em atividades diárias é praticamente inexistente, restringindo seu contato ao entretenimento e excluindo-se da rotina de cuidados e da educação dos filhos.

Essa isenção de responsabilidade fala sobre o tipo de relacionamento estabelecido entre pais e filhos nessas circunstâncias, possibilitando a criação de vínculos frágeis. Será que, após a separação, além de considerarem os cônjuges como ex, as crianças, em alguns casos, entram na categoria de ex-filhos? Estes, por sua vez, parecem acumular, ao invés de substituir pais, pois ao listarem os membros de suas famílias, incluem tanto os pais biológicos, quanto os padrastos.

Eggebeen e Knoester, (2001) revelam dados interessantes, no que diz respeito à relação dos pais biológicos, após a separação. A comunicação entre os dois costuma ser relatada como pequena, indicando que o padrão de cooperação nos cuidados infantis, tão exibido na mídia, é de fato raro. Para piorar ainda mais a situação, essa comunicação é feita, através dos filhos, que passam a intermediar o relacionamento de seus pais. Essa comunicação indireta pode indicar também uma estratégia para reduzir o desgaste e as discussões entre os adultos. No entanto, quando aumenta o envolvimento do pai não-residente com seus filhos, as reclamações da mãe sobre a pouca responsabilidade ou ausência do pai diminuem consideravelmente. King e Heard (1999) afirmam também que a satisfação materna em relação ao pai, após a separação, é um elemento crucial que irá beneficiar a adaptação do filho a essa nova situação. Dessa forma, mães infelizes e insatisfeitas podem transmitir esses sentimentos aos seus filhos.

Os pais influenciam seus filhos, tanto pelo jeito como se comportam em relação a eles, quanto pela maneira como interagem com seus ex-cônjuges. Assim, evidentemente, o relacionamento entre os pais também precisa ser considerado quando se aborda a questão das visitas feitas ao filho e do seu bem-estar. O filho que é colocado no meio do fogo cruzado entre pai e mãe pode, em algum momento, ficar confuso por não saber de quem deve gostar e em qual dos dois pode confiar.

“Quem se separa é o par amoroso, o casal conju-
gal. O casal parental continuará para sempre com
as funções de cuidar, de proteger e de prover as
necessidades materiais e afetivas dos filhos... Cos-
tumo afirmar que o pior conflito que os filhos po-
dem vivenciar, na situação da separação dos pais,
é o conflito de lealdade exclusiva, quando exigida
por um ou por ambos os pais.” (Féres-Carneiro,
1998, p.387).

King e Heard (1999) se debruçaram sobre o contexto e as condições nas quais as visitas podem promover o bem-estar das crianças. Segundo estes autores, os estudos que examinam o efeito direto do 
conflito dos pais no bem-estar dos filhos, comumente reportam uma associação negativa, embora esse efeito, em geral, não seja particularmente forte. Nem todo tipo de conflito é mau, pelo contrário, uma vez que ele pode indicar que o pai continua presente na vida de seus filhos. A ausência de conflito, em contrapartida, não necessariamente indica que os pais se dêem bem, pois, podem estar tentando evitar situações que gerem ansiedade e hostilidade. De fato, a maior parte dos relacionamentos envolve algum tipo de conflito. Ele pode variar no seu conteúdo, freqüiência, intensidade e solução, assim como no quanto as crianças são expostas diretamente a ele. No caso do conflito ser aberto e agressivo, provavelmente afetará os filhos. Por outro lado, quando os pais cooperam nos cuidados infantis, os filhos, normalmente, demonstram um ajuste positivo, independente da existência de desentendimentos entre os pais.

Embora as mães reclamem do baixo nível de envolvimento e da pouca responsabilidade assumida pelo pai que não mora mais com os filhos, essa insatisfação tende a diminuir muito quando há contato entre ele e os filhos. Dessa forma, mesmo que o aumento das visitas proporcione conflitos, também traz consigo maior satisfação por parte das mães. Essa satisfação também tende a se refletir positivamente no comportamento do pai, fato que certamente beneficia as crianças. O nível de satisfação materna é considerado importante porque influencia nas visitas e, conseqüentemente, no bem-estar dos filhos. Talvez, a situação mais benéfica para a criança seja aquela em que haja encontros freqüentes com o pai nãoresidente e em que a mãe esteja satisfeita. Em oposição, a pior situação ocorre quando as mães estão insatisfeitas, embora o pai visite seus filhos, freqüentemente. As crianças vivendo nesse contexto tendem a apresentar problemas de comportamento, o que nos faz pensar em um possível conflito de lealdade vivido por elas em relação aos pais. Essas descobertas apontam para a importância de se considerar a satisfação da mãe, quando está em jogo o bemestar de sua prole.

Marsiglio, Amato, Day e Lamb (2001), examinando vinte quatro artigos publicados desde 1990 acerca da paternidade à distância, encontraram em dez deles a correlação entre o bem-estar das crianças e o contato com o pai. Em outras dez pesquisas que buscavam averiguar o quão próximo o filho se sente de seu pai, apenas três sugeriam uma associação direta entre a proximidade do pai e o bem-estar do filho. Com isso, para estes autores, tanto a freqüência dos encontros, como os sentimentos que os filhos nutrem por seus pais, não podem ser correlacionados com o desenvolvimento da criança. Afirmam também que os contatos entre pais e filhos que não residem na mesma casa, tendem a ser voltados ao lazer, não contribuindo, de forma positiva, para o desenvolvimento dos filhos.

Como (e porque) pais não-residentes se distanciam de seus filhos é uma questão de vital importância para o entendimento do impacto do divórcio nos cuidados infantis. Parte da explicação vem da impossibilidade (consciente ou não) de apoiar o filho e parte, da inabilidade em manter relações com exparceiros. Para Stewart (1999) parece haver dificuldade do pai não-residente em se envolver e se fazer presente na rotina de seus filhos, por força de questões tanto emocionais quanto ligadas ao cotidiano. Esse afastamento também pode ser conseqüência do padrão de sucessão conjugal, no qual o pai biológico vai exercer o papel de pai social em outra família, reforçando a idéia de que os laços biológicos estão cedendo lugar aos laços sociais.

Gostaríamos de acrescentar que, além do relacionamento estabelecido entre pais e filhos, outros aspectos também devem ser considerados para que se possa contextualizar a situação de cada família específica. Por que o casal resolveu se separar? Será que a separação também não pode trazer um grande alívio para problemas enfrentados pelos membros daquela família? Ao olharmos por essa ótica, veremos que, muitas vezes, a separação traz satisfação e felicidade para os pais, que poderão servir de exemplo aos seus filhos para que eles também possam buscar relacionamentos felizes e satisfatórios. O contato entre o pai que não mora mais em casa e seu filho nos parece a melhor (única?) forma de manter e reforçar o vínculo entre ambos. O relacionamento precisa ser alimentado e a criança ter o seu lugar assegurado e respeitado. Almeida, Wethington e McDonald (2001) afirmam que o relacionamento entre pai e filho é bem mais forte, quando ambos se encontram freqüentemente, sendo que a continuidade desses encontros proporciona ao pai a capacidade 


\section{Bernardo Jablonski}

de impor disciplina ao filho.

Eggebeen e Knoester (2001) apontam para as mudanças culturais e sociais que vêm privilegiando e enaltecendo a participação do pai na vida de seus filhos. Sugerem que, hoje, estejamos presenciando um movimento em torno de uma "paternagem", muito distinta da forma como o pai era visto, em outros tempos. Para estes autores, quando um homem se torna pai, o seu comportamento tende a mudar. Muitas vezes reduz o uso de drogas, bebidas alcoólicas e execução de esportes perigosos, ao mesmo tempo em que aumenta a sua preocupação com a saúde e a segurança. Com isso, a paternidade pode tornar o homem mais responsável.

White e Gilbreth (2001) realizaram entrevistas com 189 adolescentes que têm o pai biológico vivo e que moram com a mãe e o padrasto. Essas entrevistas fornecem dados importantes no que diz respeito ao relacionamento entre o adolescente e sua mãe, pai e padrasto. O resultado mostrou uma associação positiva com a qualidade do relacionamento com os padrastos. Já o relacionamento entre o filho e o pai biológico aparece de forma um pouco menos consistente, porém, também trazendo benefícios ao desenvolvimento do adolescente. Manter um bom relacionamento, tanto com o pai biológico, como com o padrasto, de acordo com a pesquisa, está associado ao bem-estar e ao desenvolvimento saudável dos filhos.

Smock e Manning (1997), examinando os efeitos da relação do pai biológico que não possui a guarda dos filhos e o pagamento da pensão para os filhos, encontraram uma correlação consistente entre o suporte financeiro e a qualidade do relacionamento entre ambos. Para esses autores, o pagamento da pensão aos filhos é crucial para seu bem-estar, estando associado, também, aos encontros estabelecidos entre pais e filhos. Para Shapiro e Lambert (1999), os pais divorciados tendem a ficar mais deprimidos do que aqueles que permanecem casados. Podemos considerar que uma das causas seja o fato de a mulher ficar em casa com os filhos, na maioria das vezes, após a separação, mantendo a estrutura familiar criada pelo casal. Segundo Féres-Carneiro (2001), os homens recasam-se mais rapidamente do que as mulheres. Isto sugere que talvez os homens busquem, através do recasamento, o restabelecimento de uma estrutura familiar.
O principal dado levantado por Shapiro e Lambert (1999) diz respeito à co-residência, ou seja, a guarda compartilhada dos filhos, após a separação dos pais: essa situação parece ser a que propicia uma maior qualidade na relação entre o pai e seus filhos. Esse tipo de organização em que o filho possui duas residências parece algo recente, pois como vimos na pesquisa de Furstenberg e Nord (1985), esse arranjo familiar parecia mais uma fantasia exposta pela mídia do que a realidade.

De qualquer maneira, estes autores levantam a possibilidade de a guarda compartilhada dos filhos ser uma "organização familiar". Tanto a co-residência quanto a permanência do casamento são vistos de forma benéfica e positiva, pois mantêm os pais biológicos envolvidos em todos os aspectos da vida de seus filhos. Assim, não seria o divórcio que distancia os pais de seus filhos, mas o fato de os filhos não morarem mais com seus pais. Possivelmente a guarda compartilhada pode constituir um novo arranjo familiar que venha beneficiar a manutenção do vínculo entre o pai e os filhos, após a separação.

Por outro lado, os pais que vivem essa situação reportam uma certa ambivalência de sentimentos, variando entre bastante satisfação e muito estresse relacionados à responsabilidade de cuidar sozinhos dos filhos, fato que não ocorria, quando estavam casados. Todavia, essa organização familiar não parece ocorrer muito em nosso país, pois, na grande maioria dos casos de separação, os filhos ficam com as mães. Gostaríamos de lembrar o - bastante vendido livro infantil "Dois de cada” (Cole, 1997), no qual a autora cria uma situação em que os filhos, após promover o "descasamento" de seus pais, colocam a casa abaixo e, no mesmo terreno, constróem duas casas (uma para o pai e outra para a mãe) com uma passagem subterrânea que os permite transitar, livremente, de um lar para o outro. No final, os filhos concluem que é melhor ter os pais felizes, vivendo separados, do que vê-los tristes e brigando juntos. E mais, eles se beneficiam pelo fato de ter tudo em dose dupla. A arte imita a vida?

\section{Conclusões}

A família contemporânea apresenta-se multiforme e em permanente transformação. Ela vem- 
se reformulando, surgindo novas formas de relacionamentos. Inserida na sociedade, é sempre perpassada pelos valores morais, éticos, culturais, econômicos, sociais e políticos de sua época, o que se verifica com a questão de casamento e divórcio. Como a história da família não é linear, o percurso é repleto de rupturas e continuidades; assim, o que é inadmissível em um dado momento, posteriormente, pode ser aceito e absorvido pela sociedade.

A modernidade inaugurou na família a possibilidade de relacionamentos mais íntimos e afetuosos; a seguir, a entrada das mulheres no mercado de trabalho as inseriu no domínio público, e hoje, homens e mulheres são provedores de seus lares, precisam conciliar os cuidados com os filhos e promover a reformulação nas suas funções.

Há hoje uma valorização da presença do pai na vida dos filhos, que sugere o aparecimento de nova concepção de paternidade, que incorpore valores distintos dos de gerações anteriores. Com a separação e o recasamento, outros arranjos familiares precisam ser feitos para garantir o bem-estar dos filhos. E a discussão da identidade masculina impõe-se - em uma relação circular com a da paternidade - uma vez que as características do modelo tradicional de masculinidade são questionadas em prol de uma reformulação que a torne mais condizente com as demandas advindas tanto do movimento de emancipação feminina, quanto dos novos papéis na família para os quais o homem é requisitado.

Este trabalho se propôs analisar, nestes momentos de redefinição da paternidade, como pais separados constróem e mantêm o vínculo afetivo com seus filhos; verificou-se, segundo resultados das pesquisas revistas, que o relacionamento entre os pais precisa ser levado em consideração quando se pensa o bem-estar das crianças, pois o modo de eles interagirem entre si e com os filhos mostra-se muito importante, ficando intrínseco que o bom entendimento entre eles relaciona-se com a tranqüilidade e segurança dos filhos.

Quanto ao afastamento entre pais e filhos, após uma separação, podemos sugerir que a qualidade do relacionamento pode ficar abalada, quando a quantidade de tempo não é suficiente. No entanto, como mensurar o tempo suficiente? Trata-se, em verdade, de um tema muito abrangente e delicado. Outro as- pecto que não pode ser esquecido diz respeito ao intercâmbio existente no exercício das funções materna e paterna. Aparentemente, apesar de lenta, as mudanças apontam para o fato de que, atualmente, o pai e a mãe mesclam, cada vez mais, seus papéis, sendo igualmente responsáveis pelos cuidados, bem-estar e provisão das questões materiais de seus filhos.

É certo que o tema da paternidade está muito presente, dentro e fora do âmbito acadêmico, acerca da identidade masculina e da "nova paternidade". E, conforme afirmado anteriormente, a paternidade oferece ao homem a possibilidade de aprender a lidar com suas emoções e a expressá-las. Trata-se de um movimento que se está presenciando e que pode ocorrer de forma lenta, mas que, sem dúvida, já começou.

\section{Referências Bibliográficas}

Aldous, J., Mulligan, G. M. \& Bjarnason, T. (1998). Fathering over time: What makes the difference. Journal of Marriage and the Family, 60(3), 809-820.

Almeida, D. M., Wethington, E. \& McDonald, D. (2001). Daily variation in paternal engagement and negative mood: Implications for emotionally supportive and conflictual interactions. Journal of Marriage and the Family, 63 (2), 417-429.

Amato, P. P. (1994). Life-span adjustment of children to their parents' divorce. Future of Children, 4, 143-164.

Amato, P. R. \& Keith, B. (1991). Consequences of parental divorce for children's well-being: A meta analysis. Psychological Bulletin, 110, 26-46.

Amato, P. R. \& Booth, A. (1997). A generation at risk:Growing up in an era of family upheaval. Cambridge: Harvard University Press.

Arditti, J. A. (1999). Rethinking relationships between divorced mothers and their children: Capitalizing on family strengths. Family Relations, 48, 109119.

Atkinson, M. P. \& Blackwelder, S.P. (1993) Fathering in the 20th Century. Journal of Marriage and the Family, 55, 4, 975-986. 
Bertaux, D. \& Delcroix, C. (1992). Where have all the daddies gone? Em U. Bjornberg (org.), European parents in the 1990's (p. 181-196). Brunswick: Transaction.

Boechat, W. (1997). Arquétipos masculinos: Animus Mundi. Em W. Boechat (org.), O masculino em questão. Rio de Janeiro: Editora Vozes

Brasileiro, R. F., Jablonski, B. \& Féres-Carneiro, T. (2002). Papéis de Gênero e a Transição para a Parentalidade. PSICO, 33, 2, 289-310.

Bryant, W. K. \& Zick, C. D. (1996). An Examination of Parent-Child Shared Time. Journal of Marriage and the Family, 58 (1), 227-237.

Cole, B. (1997). Dois de cada. São Paulo: Ática.

Coontz, S. (1997). The way we really are: coming to terms with America's changing families. New York: Basic Books

Corneau, G. (1995). Paternidade e masculinidade. Em S. Nolasco (org.), A desconstrução do masculino (pp 43-52). Rio de Janeiro: Rocco

Coverman, S. \& Shelley, J. F. (1986). Change in Men's Housework and Child-Care Time, 19651975. Journal of Marriage and the Family, 48(3), 413-422.

Cowan, P. A. \& Cowan, C. P. (2000). When partners become parents: the big life change for couples. New Jersey: Lawrence Erlbaum Associates.

Dantas, C. R. (2003). O Exercício da paternidade após a separação. Dissertação de Mestrado. PUC-Rio.

Demo, D. H. (1992). Parent-Child Relations: Assessing Recent Changes. Journal of Marriage and the Family, 54(1), 104-117.

Dorais, M. (1994). O homem desamparado. São Paulo: Loyola.

Eggebeen, D. \& Knoester, C. (2001). Does fatherhood matter for men? Journal of Marriage and the Family, 63(2), 381-393.

Fein, R. (1978). Research on fathering: social policy and emergent perspective. Journal of Social Issues, 34(1), 122-135.
Felzenszwalb, M. (2003). Partenogênese - Os efeitos da exclusão do pai no desenvolvimento da personalidade e na dinâmica familiar. Tese de Doutorado, IMS/UERJ.

Féres-Carneiro, T. (1998). Casamento contemporâneo: O difícil convívio da individualidade com a conjugalidade. Psicologia: Reflexão e Crítica, 11(2), 379-394.

Féres-Carneiro, T. (2001). Casamento contemporâneo: Constituição da identidade conjugal. Em T. FéresCarneiro (org.), Casal e família: Do social à clínica (pp.67-80). Rio de Janeiro: NAU.

Furstenberg, F. \& Nord, C. (1985). Parenting apart: patterns of childrearing after marital disruption. Journal of Marriage and the Family, 47, 893904.

Glick, P. C. (1984). Marriage, divorce, and living arrangements: prospective changes. Journal of Family Issues, 5(1), 7-26.

Goldenberg, M. (2000). O macho em crise: um tema em debate dentro e fora da academia. Em M. Goldenberg (org.), Os novos desejos (pp. 1539). Rio de Janeiro: Record.

Greenberg, E. \& O’Neill, R. (1990). Parents’ concerns about their child's development: Implications for fathers'and mothers' well-being and attitudes towards work. Journal of Marriage and the Family, 52, 621-635.

Jablonski, B. (1998). Até que a vida nos separe - a crise do casamento contemporâneo. Rio de Janeiro: Agir.

Jablonski, B. (1999). Identidade masculina e o exercício da paternidade: de onde viemos e para onde vamos. Em T. Féres-Carneiro (org.), Casal e família: Entre a tradição e a transformação (pp.55-69). Rio de Janeiro: NAU.

King, V. \& Heard, H. (1999). Nonresident father visitation, parental conflict, and mother's satisfaction: What's best for child well being? Journal of Marriage and the Family, 61, 385396.

LaRossa, R., Gordon, B. A., Wilson, R. J., Bairan, A. 
\& Jaret, C. (1991). The Fluctuating Image of the 20th Century American Father. Journal of Marriage and the Family, 53(4), 987-997.

Le Monde (2000). Famille: les noveaux pères ont disparu. Edição de 27/05/2000.

Lewis, C. \& Dessen, M. A. (1999). O pai no contexto familiar. Psicologia: Teoria e Pesquisa, 15, 9-16.

Marsiglio, W., Amato, P., Day, R. \& Lamb, M. (2001). Scholarship on fatherhood in the 1990s and beyond. Em R. M. Milardo (Org.), Understanding families into the new millennium: A decade in review. National Council on Family Relations (pp.392-410). Minneapolis: Minnesota.

Nolasco, S. (1993). O mito da masculinidade. Rio de Janeiro: Rocco.

Nolasco, S. (1995). A desconstrução do masculino. Rio de Janeiro: Rocco.

Nolasco, S. (2000). De Tarzan a Homer Simpson: Banalização e Violência Masculina em Sociedades Contemporâneas. Tese de Doutorado, PUC-Rio, 2000.

Oliveira, P. (1998). Discursos sobre a masculinidade. Estudos Feministas, n $1 / 98,91-112$.

Phares, V. (1996). Fathers and Developmental Psychopathology. New York: J. Wiley.

Pleck, J. H. (1997). Paternal envolvement: Levels, sources and consequences. Em M.E. Lamb (Org.), The role of the father in the child development. (pp.66-103). New York: Wiley.

Ramires, V. (1997). O exercício da paternidade hoje. Rio de Janeiro: Rosa dos Tempos.

Russel, G. (1978). The father role and its relation to masculinity, femininity and androgyny. Child Development,49, 1174-1181.

Salem, T. (1987). Sobre o casal grávido. Incursão em um universo ético. Tese de doutorado. Rio de Janeiro: PPGAS/UFRJ.

Sanchez, L. \& Thompson, L. (1997). Becoming mothers and fathers: parenthood, gender, and the division of labor. Gender \& Society 11, 747-772.
Shapiro, A. \& Lambert, J. (1999). Longitudinal effects of divorce on the quality of the father-child relationship and on father's psychological well being. Journal of Marriage and the Family, 61, 397-408.

Smock, P. \& Manning, W. (1997). Nonresident parents' characteristics and child support. Journal of Marriage and the Family, 59, 798-808.

Souza, R.M. (2000). Depois que papai e mamãe se separara: um relato dos filhos. Psicologia: Teoria e Pesquisa, 16(3), 203-211.

Stewart, S. (1999). Nonresident mothers' and fathers' social contact with children. Journal of Marriage and the Family, 61, 894-907.

Walzer, S. (1998). Thinking about the baby; Gender and transition into parenthood. Philadelphia: Temple University Press.

White, L. \& Gilbreth, G. (2001). When children have two fathers: Effects of relationships with stepfathers and noncustodial fathers o adolescent outcomes. Journal of Marriage and the Family, 63(1), 155-167.

Winnicott, D. W. (1982). A criança e seu mundo. Rio de Janeiro: Zahar. 